\title{
Do Benefits Outweigh Risks for Corticosteroid Therapy in Acute Exacerbation of Chronic Obstructive Pulmonary Disease in People with Diabetes Mellitus?
}

This article was published in the following Dove Press journal:

International Journal of Chronic Obstructive Pulmonary Disease

\author{
Ali M Aldibbiat $\mathbb{I D}^{1,2}$ \\ Ahmed Al-Sharefi iD ${ }^{3}$ \\ 'Dasman Diabetes Institute, Kuwait City, \\ Kuwait; ${ }^{2}$ Institute of Cellular Medicine, \\ Newcastle University, Newcastle upon \\ Tyne, UK; ${ }^{3}$ Metabolic and Diabetes Unit, \\ Sunderland Royal Hospital, South \\ Tyneside and Sunderland NHS \\ Foundation Trust, Sunderland, UK
}

\begin{abstract}
Chronic obstructive pulmonary disease (COPD) and diabetes mellitus (DM) are chronic health conditions with significant impacts on quality and extent of life. People with COPD and DM appear to have worse outcomes in each of the comorbid conditions. Treatment with corticosteroids in acute exacerbation of COPD (AECOPD) has been shown to reduce treatment failure and exacerbation relapse, and to shorten length of hospital stay, but not to affect the inexorable gradual worsening of lung function. Treatment with corticosteroids can lead to a wide spectrum of side effects and complications, including worsening hyperglycemia and deterioration of diabetes control in those with pre-existing DM. The relationship between COPD and DM is rather complex and accumulating evidence indicates a distinct phenotype of the comorbid state. Several randomized controlled trials on corticosteroid treatment in AECOPD excluded people with DM or did not report on outcomes in this subgroup. As such, the perceived benefits of corticosteroids in AECOPD in people with DM have not been validated. In people with COPD and DM, the detrimental side effects of corticosteroids are guaranteed, while the benefits are not confirmed and only presumed based on extrapolation from the general COPD population. Therefore, the potential for harm when prescribing corticosteroids for AECOPD in people with DM cannot be excluded.
\end{abstract}

Keywords: COPD, acute exacerbation of COPD, corticosteroids, metabolic syndrome, hyperglycemia, diabetes mellitus

\section{Introduction}

The incidence of chronic obstructive pulmonary disease (COPD) is increasing worldwide, and the burden is escalating because of the high rate of direct and passive tobacco smoking, compounded by air pollution from biomass fuels and other industrial pollutants. It is estimated that COPD affects 251 million individuals worldwide and contributed to 3.17 million related deaths in $2017 .^{1}$ Patients with COPD often suffer from multiple comorbidities linked directly or indirectly to COPD, such as cardiovascular disease, arthritis, mental health disorders, metabolic syndrome, and type 2 diabetes mellitus (T2DM). ${ }^{2-5}$ Patients with COPD often experience recurrent acute exacerbations requiring emergency treatment either in the community or in hospital. Acute exacerbation of COPD (AECOPD) is a major health burden to patients, their families, healthcare systems, and society. This is mostly notable in winter, when incidences of respiratory tract infections are high.
Correspondence: Ali M Aldibbiat

Dasman Diabetes Institute, Sharq, Block

3, P.O. Box II80, Dasman 15462, Kuwait

Tel +96522242999 Ext. 2214

Fax +96522492436

Email ali.aldibbiat@dasmaninstitute.org 
Metabolic syndrome is a cluster of insulin resistance with glucose intolerance, hypertension, dyslipidemia, and obesity, with a strong link to increased cardiovascular morbidity and development of T2DM. ${ }^{6}$ Those with metabolic syndrome have up to 24.5-fold increased risk of developing T2DM with overt hyperglycemia, ${ }^{7}$ and $50-72 \%$ of those with T2DM have metabolic syndrome. ${ }^{8,9}$ Both metabolic syndrome and diabetes mellitus (DM) are on the rise as a pandemic global health concern. DM currently affects 425 million people worldwide, with an estimated increase to 629 million by $2045 .{ }^{10}$ Metabolic syndrome is estimated to affect three times the number of DM cases. ${ }^{11}$ While genetic predisposition, sedentary lifestyle, chronic inflammation, and excessive calorie intake play major roles in the development of T2DM, drug-induced hyperglycemia and DM are very well recognized. Several classes of drugs are implicated in insulin resistance and beta-cell dysfunction leading to hyperglycemia and diabetes, the commonest of which are calcineurin inhibitors, thiazides, statins, and corticosteroids. ${ }^{12}$ People with DM, especially those with poor glycemic control, are at high risk of developing complications that affect multiple systems, leading to retinopathy, nephropathy, neuropathy, peripheral vascular disease, coronary artery disease, and cerebrovascular disease. Significant reduction of such risks can be achieved when stringent DM control is achieved early. ${ }^{13-17}$

Both COPD and DM are chronic health conditions with the prospect for deterioration over time. It is estimated that $10 \%$ of people with DM suffer from COPD ${ }^{18-20}$ (Figure 1), and $17-50 \%$ of people with COPD are at risk of developing $\mathrm{DM}^{21,22}$ The prevalence of metabolic syndrome in people with COPD was reported to be $34 \%{ }^{23}$ (Figure 1). Moreover, an alarming 5-year mortality risk in people with COPD and DM has been reported to be 1 in $5 .{ }^{24}$ The exact mechanism which links COPD to metabolic syndrome and DM is not straightforward and there is accumulating evidence indicating a distinct phenotype of COPD and DM comorbid state. ${ }^{25}$ Huang et al reported significantly higher high-mobility group box-1 (HMGB1) levels in people with COPD and DM compared to people with COPD or DM alone and to healthy people. ${ }^{26}$ HMGB1 is a late inflammatory mediator which belongs to the damage-associated molecular pattern (DAMP) family. It attracts active immune cells by attaching to pattern recognition receptors (PRRs), which play a central role in innate immune responses. ${ }^{27}$ It is not clear what causes this HMGB1 rise, although a shared inflammatory pathogenesis between COPD and DM can be speculated. Similarly, the chronic inflammatory state in COPD marked by the rise in

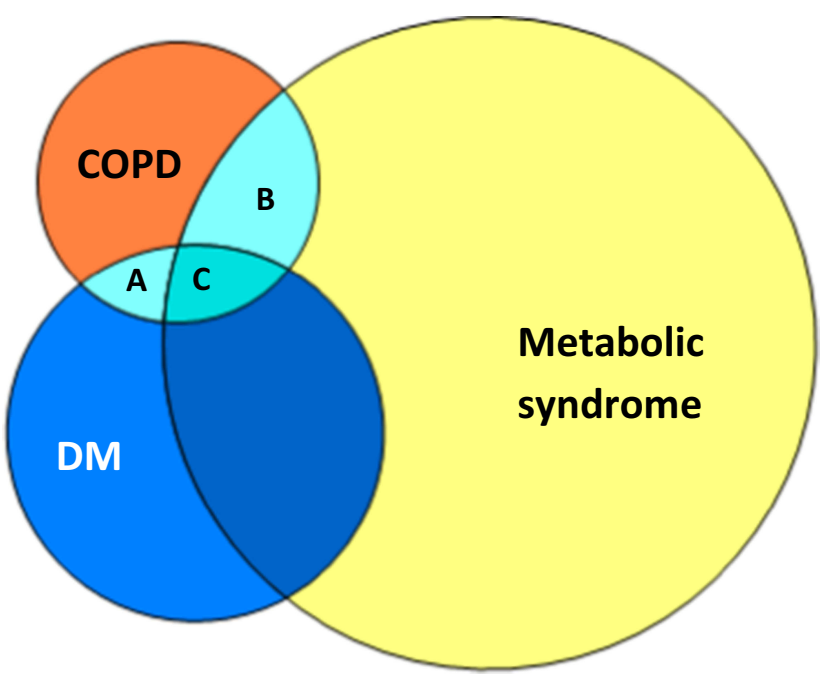

Figure I Venn diagram demonstrating overlap between COPD (orange circle, 251 million $^{\prime}$ ), DM (blue circle, 425 million $^{10}$ ), and metabolic syndrome (yellow circle, 1275 million ${ }^{11}$ ). The prevalence of DM and COPD is estimated at 43 million $^{18-20}$ (area $A+C)$, metabolic syndrome and COPD at 85 million $^{23}$ (area B+C), and COPD with DM and/or metabolic syndrome (area $A+B+C)$ at 107 million.

inflammatory markers such as C-reactive protein (CRP), interleukin-6 (IL-6), tumor necrosis factor- $\alpha$ (TNF- $\alpha$ ), and soluble factor-I has been suggested as a contributor to the rise of metabolic syndrome and hyperglycemia. ${ }^{28}$ Moreover, the sedentary lifestyle known to be a risk factor for metabolic syndrome and T2DM is common in people with COPD, especially when disease is advanced. ${ }^{29}$ Finally, the iatrogenic hyperglycemia resulting from systemic corticosteroid therapy in AECOPD is quite pronounced in this patient group, indicating an existing predisposition to corticosteroid-induced hyperglycemia, a phenomenon that is noted in only $36 \%$ of the people who receive three or more oral corticosteroid prescriptions for different indications. ${ }^{30}$ In this review, we examine the evidence for corticosteroid use in the AECOPD, concentrating on patients with both COPD and DM.

\section{Metabolic and Diabetogenic Impact of Corticosteroids}

The clinical utility of corticosteroids is wide owing to their anti-inflammatory and immunomodulatory properties. Corticosteroids are used in many autoimmune and inflammatory conditions, such as connective tissue disease, asthma, vasculitis, and inflammatory bowel disease, in addition to their use as part of immune-suppression regimens in different types of transplantations. ${ }^{31,32}$ Corticosteroids are associated with a wide spectrum of side effects, including mood changes, skin thinning, hypertension, adrenal suppression leading to dependence on exogenous steroids, osteoporosis, 
hyperglycemia, and DM. ${ }^{33-36}$ These side effects occur more often with prolonged use ${ }^{37}$ and higher doses. ${ }^{38}$ Corticosteroids can induce hyperglycemia by interfering with several components of the glucose regulation pathway in different organs of the body, including inhibition of insulin secretion from pancreatic beta-cells, ${ }^{39}$ increasing glucagon release from pancreatic alpha cells, ${ }^{40}$ and impairing glucose transporter-4 (GLUT-4) translocation to the cell surface in myocytes, a crucial step for glucose uptake and utilization. ${ }^{41}$ Moreover, corticosteroids reduce the expression and phosphorylation of insulin receptor substrate-1 (IRS-1) and phosphatidylinositol 3-kinase (PI3-K), resulting in further impairment of insulin-mediated glucose uptake by the myocytes. ${ }^{41}$ Corticosteroids suppress phosphoenolpyruvate carboxykinase (PEPCK) enzyme in lipocytes and augment its action in hepatocytes, which results in an elevation in the level of free fatty acids, leading to a state of relative insulin resistance. ${ }^{42,43}$ These diabetogenic effects of corticosteroids have been demonstrated ubiquitously in the literature. Administration of oral prednisolone at a similar dose and duration to those often recommended for COPD exacerbations was found to be associated with higher fasting glucose and a measured decline in beta-cell function in otherwise healthy subjects. ${ }^{44}$ In a randomized double-blinded placebocontrolled trial, 2-week administration of either a low dose of prednisolone (7.5 mg daily) or higher doses (30 mg daily) resulted in a reduction in the ability of insulin to suppress endogenous glucose production, with a reduction in lipolysis and an increase in whole-body proteolysis. ${ }^{45}$ The metabolic compromise induced by corticosteroids can be as serious as the development of diabetic ketoacidosis (DKA), even in individuals with no prior diagnosis of DM. ${ }^{46}$

Treatment with systemic corticosteroids in those with established DM necessitates pre-emptive intensification of diabetes treatment in order to counteract the expected hyperglycemic effect of corticosteroids. An important example of such an approach is in pregnant women with DM who require corticosteroid therapy for fetal lung maturation in cases of threatened preterm labor, where insulin doses are increased by up to $60 \%$ in order to counteract the hyperglycemic effect of corticosteroids and maintain glycemic balance. ${ }^{47}$

\section{Corticosteroids and DM in Patients with COPD}

Corticosteroid therapy plays a central role in the acute and long-term management of COPD. In a large retrospective cohort study comparing 9,342 patients with COPD without exacerbations and 4,671 patients with newly diagnosed AECOPD, it was found that the incidence of DM was higher in those patients who suffer exacerbations compared to those with stable COPD during the follow-up years. ${ }^{48}$ It is difficult to draw firm conclusions from this association; however, the increased incidence of diabetes could be attributed, at least in part, to the shared phenotype theory and the frequent courses of oral high-dose corticosteroids given at each episode of AECOPD. Similar observations were reported with inhaled corticosteroids in a cohort study involving 388,584 patients with respiratory diseases, where inhaled corticosteroids were associated with $34 \%$ increased risk of development of DM and worsening of pre-existing diabetes, necessitating insulin therapy. ${ }^{49}$ The risk increased to $64 \%$ when patients received higher doses of inhaled corticosteroids such as fluticasone $1,000 \mu \mathrm{g}{ }^{49}$ In a casematched UK primary care cohort study comparing people with T2DM and COPD to people with T2DM alone, those who received inhaled corticosteroids had worse diabetes control after 12-18 months of follow-up. ${ }^{50}$ Moreover, in a retrospective analysis of 18,266 patients with diabetes from the administrative claims data by the Australian Government Department of Veterans' Affairs, there was up to $94 \%$ increased likelihood of DM-related hospital admissions in patients with COPD who used high-dose corticosteroids. ${ }^{20}$

In a double-blind randomized placebo-controlled trial involving hospital admissions with AECOPD, systemic corticosteroids given for 2 or 8 weeks were found to be superior than placebo in reducing hospital stay from 9.7 to 8.5 days $(p=0.04)$, and treatment failure from $33 \%$ to $23 \%$ $(p=0.04)$. However, there was a significant onset of hyperglycemia requiring initiation of diabetes treatment in the corticosteroid groups. This was associated with prolonged hospital stay and even high rates of rehospitalization because of infections. ${ }^{51}$ This is a very important result as the significant benefits seen in the overall study cohort appear to have been offset when corticosteroids resulted in significant hyperglycemia.

\section{Hyperglycemia and DM Impact on Patients with COPD}

Several studies have suggested that the development of T2DM can worsen lung function in patients with COPD ${ }^{52-55}$ Even in the absence of COPD, the development of metabolic syndrome, insulin resistance, and systemic 
inflammation can be risk factors for deterioration in lung function in otherwise healthy non-smoking individuals. ${ }^{56}$ In addition to worsening lung function, exercise capacity and functional status were adversely affected in individuals with DM and COPD across all functional stages of COPD, ${ }^{57}$ in addition to worse prognosis and higher risk of mortality. ${ }^{58}$

Hyperglycemia can lead to a vicious cycle in patients with COPD and DM, predisposing to further exacerbations and therefore triggering the need for systemic corticosteroids, which in turn lead to hyperglycemia (Figure 2). The mechanisms through which hyperglycemia and DM negatively impact lung function and COPD outcomes are not fully understood; however, several pathways have been implicated (Figure 3). Impairment of the humoral innate immunity in DM increases the risk and severity of infections. ${ }^{59,60}$ Moreover, increased oxidative stress in poorly controlled DM increases susceptibility to bacterial infections. ${ }^{61}$ The state of systemic inflammation seen in both DM and COPD leads to microangiopathy, resulting in alterations in lung parenchyma, with fibrosis and thickening of the basal lamina, which manifest in restrictive lung defects. ${ }^{52,62,63}$ Poorly controlled DM leads to increased glucose levels in the airway fluids, providing a favorable environment for bacterial infections and colonization. ${ }^{64}$ It is interesting to note that the airways in COPD appear to be leaky of glucose compared to those in people with no COPD, even in the absence of DM, with much higher glucose levels detected in sputum samples during AECOPD compared to stable COPD. ${ }^{65}$ The state of

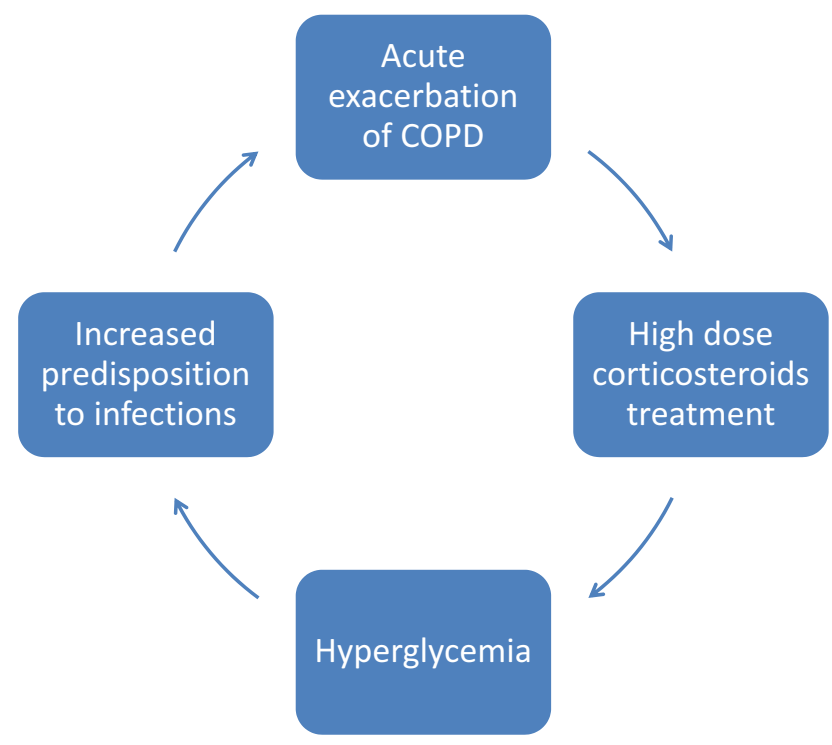

Figure 2 The self-perpetuating cycle of AECOPD treated with corticosteroids which leads to hyperglycemia, which in turn increases airway predisposition to infections.

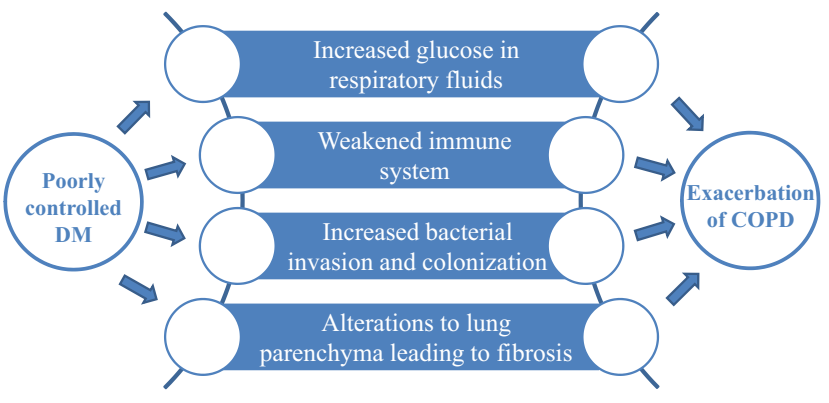

Figure 3 Factors through which poorly controlled diabetes mellitus contributes to increased susceptibility for AECOPD and deterioration of COPD.

hyperglycemia in patients with COPD can increase the risk of subsequent pulmonary infections and may be implicated in treatment failure in those with infective exacerbations. In one study, it was found that hyperglycemia in patients admitted with AECOPD was associated with failure of noninvasive ventilation and the subsequent development of pulmonary infections and poor outcomes. ${ }^{66}$ Furthermore, the presence of a comorbid state of insulin-treated DM and COPD was linked to longer hospital stay and a higher prevalence of Gram-negative bacteria in the sputum culture. ${ }^{67}$ The above observations are quite relevant in clinical practice and highlight the need to avoid, or at least mitigate, hyperglycemia in people with DM and COPD.

\section{Corticosteroids in COPD Exacerbations: Evidence and Guidelines}

Evidence for the use of high-dose corticosteroids in AECOPD has accumulated over several decades. Despite the limited impact on overall mortality and disease progression, corticosteroids have been shown to reduce treatment failure and relapse rates, improve lung function, and reduce length of hospital stay. ${ }^{51,68,69}$ Earlier systematic reviews concluded the merit of $30-40 \mathrm{mg}$ of oral prednisolone for 7-14 days to treat AECOPD. ${ }^{70,71}$ In an attempt to evaluate whether shorter courses of corticosteroids can attain equivalent clinical outcomes, Leuppi et al conducted a placebocontrolled double-blind randomized controlled trial (RCT) comparing 5 and 14 days of high-dose corticosteroid courses in 314 patients with AECOPD attending five Swiss teaching hospitals. Pleasingly, COPD outcomes were non-inferior in the shorter duration arm compared to the longer duration arm at 6 months' follow-up. ${ }^{72}$

Benefits from oral corticosteroid therapy in stable COPD have not been established or recommended. A transient improvement in lung function was seen when 
stable COPD patients were treated daily with a high (30 mg), but not a low (10-15 mg), daily dose of prednisolone. This benefit was only brief. ${ }^{73}$ As expected with long-term corticosteroid therapy, the use of oral corticosteroids in patients with stable COPD was found to be associated with significant adverse side effects, leading to multiple comorbidities including myopathy, respiratory muscle weakness, osteoporosis, and DM. Sustaining these comorbidities may have contributed to the reduced survival. ${ }^{73-76}$ On the other hand, inhaled corticosteroids have been shown to be beneficial in reducing the frequency of COPD exacerbations in those with raised blood eosinophil count, ${ }^{77}$ but survival only improved when combination therapy with inhaled long-acting bronchodilators was given. $^{78}$

Based on such evidence, clinical guidelines recognize oral corticosteroid therapy as a cornerstone in the management of AECOPD. ${ }^{79-81}$ In a guideline review which included the updated versions of 19 guidelines up to May 2014, Laue et al reported that almost all guidelines recommended corticosteroids for all people with AECOPD. ${ }^{82}$ Most recently, the UK National Institute for Health and Care Excellence (NICE) COPD guideline [December 2018, with update in July 2019] advocated the use of $30 \mathrm{mg}$ prednisolone for 5 days for AECOPD in the absence of significant contraindications. ${ }^{81}$ However, such significant contraindications were not defined and were left to the discretion of the attending doctors. The guideline clearly recognized potential long-term complications of corticosteroids, and recommended regular surveillance and treatment for complications such as osteoporosis, while DM was missed out in the guideline as a potential complication that warrants surveillance and treatment.

The Joint American Thoracic Society/European Respiratory Society guideline 2017 recommended treating AECOPD in the community with prednisolone therapy for a longer period (9-14 days) to help improve lung function and reduce rehospitalizations. ${ }^{79}$ In the Global Initiative for Obstructive Lung Disease (GOLD) guideline 2019, the recommendation for corticosteroid therapy in AECOPD was for 5-7 days, especially in those with elevated eosinophil count, although no specific recommendation was given for those with COPD and DM. ${ }^{77}$

There are several caveats to these recent and earlier guidelines (reviewed by Laue et $\mathrm{al}^{82}$ ). First, the clinical trials upon which these guidelines were based were selective in which patients were included, and they do not represent real-world patients. A number of the RCTs excluded people with pre-existing DM, or simply did not account for the effect of hyperglycemia on trial outcomes. $^{83-85}$ In one RCT evaluating the effect of corticosteroids in AECOPD which included people with DM, there were more subjects with DM in the control arm than in the corticosteroid arm, which would have confounded the results. ${ }^{84}$ It is not safe to consider the outcomes of such trials applicable to those with DM. Second, there was heterogeneity in the settings of these trials, with some taking place in hospitals, others taking place in the community, and others including a mix of community and hospital patients. ${ }^{68}$ Third, the diagnosis of AECOPD was based on symptoms such as increased dyspnea, cough, and increased sputum production. This is subjective and does not necessarily link these symptoms directly to COPD etiology, such as when subjects with COPD suffer from anxiety or decompensation of heart failure, which are common in people with COPD. Finally, advice for the use of inhaled and oral corticosteroids in COPD is not focused because of a lack of phenotypic classification of COPD and exacerbations. For these reasons, it is likely that the clinical guidelines are contributing to the overprescription of corticosteroids in patients with COPD.

\section{Conclusions, Considerations, and Future Recommendations}

The benefits of corticosteroid-based therapies in patients with COPD are very well established. However, the "one size fits all" approach to corticosteroid use in COPD is not entirely evidence based, and the generous and unselective use of oral corticosteroids in the treatment of AECOPD is not without harm. Corticosteroids have proven side effects on repeated and continuous exposure, while benefits in AECOPD are not confirmed in COPD with certain other comorbidities such as DM. Neither those with COPD and DM nor those with COPD and corticosteroid-induced hyperglycemia have been studied to assess the benefits of corticosteroids in AECOPD, and the balance of benefit/harm has not been established. It is not safe to extrapolate the benefits of systemic high-dose corticosteroids in AECOPD to those with DM, especially when such treatment can be detrimental to DM and is guaranteed to derail glycemic control. As such, the pulmonary benefits from corticosteroids in AECOPD will be offset, at least in part, by the negative impact on DM, and therefore overall patient outcomes in such cases remain to be determined. There is an urgent need for large prospective trials looking 
into the metabolic and COPD outcomes in patients with the comorbid state in order to re-evaluate the balance of short- and long-term benefits/risks of oral corticosteroids. Similarly, more research into the benefits of corticosteroid in COPD with other comorbid states is needed, such as in those with steroid-induced hyperglycemia, those with metabolic syndrome, and those with cardiovascular disease. Phenotyping and objective confirmation of AECOPD and etiology, aided by biomarkers such as procalcitonin or eosinophil count, can open up the possibility for trials of focused therapeutic choices in the future, leading to more personalized medicine. ${ }^{34,86,87}$

In the meantime, the treatment and prevention of AECOPD remain the top priority, and if corticosteroids are used in patients with DM, then active diabetes treatment modification should be sought with the support of the diabetes care team. This approach should be integrated into COPD care pathways and guidelines both in hospitals and in community settings. Moreover, in those with COPD and no confirmed DM, regular surveillance for diabetes should become part of routine COPD care, given the increased risk. Collaborative work between respiratory teams and diabetes teams will benefit the overall care and outcomes in people with COPD and DM. When DM is missed, or not considered when corticosteroid treatment is given, an opportunity to intervene and mitigate hyperglycemia is lost and the potential for doing harm is therefore possible.

\section{Authors' Disclaimer}

The opinions presented in this manuscript reflect the authors' own viewpoints.

\section{Disclosure}

Both authors declare no relevant conflicts of interest for this work.

\section{References}

1. World Health Organisation. COPD factsheet. Fact Sheets; 2017. Available from: http://www.who.int/news-room/fact-sheets/detail/ chronic-obstructive-pulmonary-disease-(copd). Accessed January 7, 2019.

2. Cavaillès A, Brinchault-rabin G, Dixmier A, et al. Comorbidities of COPD. Eur Respir Rev. 2013;22:454-475. doi:10.1183/09059180.00 008612

3. Chatila WM, Thomashow BM, Minai OA, Criner GJ, Make BJ. Comorbidities in chronic obstructive pulmonary disease. Proc Am Thorac Soc. 2008;5(4):549-555. doi:10.1513/pats.200709-148ET

4. McAuley SA, Horsburgh JC, Ward GM, et al. Insulin pump basal adjustment for exercise in type 1 diabetes: a randomised crossover study. Diabetologia. 2016;59:1636-1644. doi:10.1007/s00125-0163981-9
5. Vanfleteren LEGW. Does COPD stand for "COmorbidity with Pulmonary Disease"? Eur Respir J. 2015;45(1):14LP- 17. doi:10. 1183/09031936.00148014

6. Shin JA, Lee JH, Lim SY, et al. Metabolic syndrome as a predictor of type 2 diabetes, and its clinical interpretations and usefulness. J Diabetes Investig. 2013;4:334-343. doi:10.1111/jdi.12075

7. Sattar N, Gaw A, Scherbakova O, et al. Metabolic syndrome with and without $\mathrm{C}$-reactive protein as a predictor of coronary heart disease and diabetes in the West of Scotland Coronary Prevention Study. Circulation. 2003;108:414-419. doi:10.1161/01.CIR.0000080897.52664.94

8. Kengne AP, Limen SN, Sobngwi E, Djouogo CFT, Nouedoui C. Metabolic syndrome in type 2 diabetes: comparative prevalence according to two sets of diagnostic criteria in sub-Saharan Africans. Diabetol Metab Syndr. 2012;4. doi:10.1186/1758-5996-4-22.

9. Garcia Lira Neto JC, de Almeida Xavier M, Jwp B, et al. Prevalence of metabolic syndrome in individuals with type 2 diabetes mellitus. Rev Bras Enferm. 2017;70(2):0145. doi:10.1590/0034-7167-2016-0145

10. International Diabetes Federation. IDF Diabetes Atlas Eighth Edition 2017; 2017. doi:10.1016/j.diabres.2009.10.007

11. Saklayen MG. The Global Epidemic of the Metabolic Syndrome. Curr Hypertens Rep. 2018;20. doi:10.1007/s11906-018-0812-z.

12. Fathallah N, Slim R, Larif S, Hmouda H, Ben Salem C. DrugInduced Hyperglycaemia and Diabetes. Drug Saf. 2015;38:11 53-1168. doi:10.1007/s40264-015-0339-z

13. Holman RR, Paul SK, Bethel MA, Matthews DR, Neil HA. 10-year follow-up of intensive glucose control in type 2 diabetes. $N$ Engl J Med. 2008;359:1577-1589. doi:10.1056/NEJMoa0806470

14. Clarke PM, Gray AM, Briggs A, et al. A model to estimate the lifetime health outcomes of patients with Type 2 diabetes: the United Kingdom Prospective Diabetes Study (UKPDS) Outcomes Model (UKPDS no. 68). Diabetologia. 2004;47:1747-1759. doi:10. 1007/s00125-004-1527-z

15. DCCT Study Group. Diabetes Control and Complications Trial (DCCT). Update. DCCT Research Group. Diabetes Care. 1990;13 (4):427-433. doi:10.2337/diacare.13.4.427

16. Gubitosi-klug RA, Lachin JM, Backlund JYC, Lorenzi GM, Brillon DJ, Orchard TJ. Intensive diabetes treatment and cardiovascular outcomes in type1 diabetes: the DCCT/EDIC study 30-year follow-up. Diabetes Care. 2016;39(5):686-693. doi:10.2337/dc15-1990

17. King P, Peacock I, Donnelly R. The UK Prospective Diabetes Study (UKPDS): clinical and therapeutic implications for type 2 diabetes. Br J Clin Pharmacol. 1999;48(5):643-648. doi:10.1046/j.1365-2125. 1999.00092.x

18. Gläser S, Krüger S, Merkel M, Bramlage P, Herth FJF. Chronic obstructive pulmonary disease and diabetes mellitus: a systematic review of the literature. Respiration. 2015;89(3):253-264. doi:10.1159/000369863

19. Kerr EA, Heisler M, Krein SL, et al. Beyond comorbidity counts: how do comorbidity type and severity influence diabetes patients' treatment priorities and self-management? J Gen Intern Med. 2007;22(12):1635-1640. doi:10.1007/s11606-007-0313-2

20. Caughey GE, Preiss AK, Vitry AI, Gilbert AL, Roughead EE. Comorbid diabetes and COPD: impact of corticosteroid use on diabetes complications. Diabetes Care. 2013;36(10):3009-3014. doi:10.2337/ dc12-2197

21. Malte Rasmussen S, Brok J, Backer V, Francis Thomsen S, Meteran H. Association between chronic obstructive pulmonary disease and type 2 diabetes: a systematic review and meta-analysis. COPD J Chronic Obstr Pulm Dis. 2018;15:526-535. doi:10.1080/15412555.2018.1532495

22. Mannino DM, Thorn D, Swensen A, Holguin F. Prevalence and outcomes of diabetes, hypertension and cardiovascular disease in COPD. Eur Respir J. 2008;32:962-969. doi:10.1183/09031936.00012408

23. Cebron Lipovec N, Beijers RJHCG, van den Borst B, Doehner W, Lainscak M, Schols AMWJ. The prevalence of metabolic syndrome in chronic obstructive pulmonary disease: a systematic review. COPD J Chronic Obstr Pulm Dis. 2016;13:399-406. doi:10.3109/ 15412555.2016.1140732 
24. Aramburu A, Arostegui I, Moraza J, et al. COPD classification models and mortality prediction capacity. Int $J$ COPD. 2019;14:605-613. doi:10.2147/COPD.S184695

25. Pikoula M, Quint JK, Nissen F, Hemingway H, Smeeth L, Denaxas S. Identifying clinically important COPD sub-types using data-driven approaches in primary care population based electronic health records. BMC Med Inform Decis Mak. 2019;19. doi:10.1186/ s12911-019-0805-0.

26. Huang J, Zeng T, Tian Y, et al. Clinical significance of high-mobility group box-1 (HMGB1) in subjects with type 2 diabetes mellitus (T2DM) combined with chronic obstructive pulmonary disease (COPD). J Clin Lab Anal. 2019;33. doi:10.1002/jcla.22910

27. Amarante-mendes GP, Adjemian S, Branco LM, Zanetti LC, Weinlich R, Bortoluci KR. Pattern recognition receptors and the host cell death molecular machinery. Front Immunol. 2018;9. doi:10.3389/fimmu.2018.02379.

28. Bolton CE, Evans M, Ionescu AA, et al. Insulin resistance and inflammation - A further systemic complication of COPD. COPD J Chronic Obstr Pulm Dis. 2007;4:121-126. doi:10.1080/15412550701341053

29. Park SK, Larson JL. The relationship between physical activity and metabolic syndrome in people with chronic obstructive pulmonary disease. J Cardiovasc Nurs. 2014;29:499-507. doi:10.1097/JCN.000 0000000000096

30. Gulliford MC, Charlton J, Latinovic R. Risk of diabetes associated with prescribed glucocorticoids in a large population. Diabetes Care. 2006;29:2728-2729. doi:10.2337/dc06-1499

31. van Sandwijk MS, Bemelman FJ, Ten Berge IJM. Immunosuppressive drugs after solid organ transplantation. Neth J Med. 2013;71(6):281-289.

32. Quellmann S, Schwarzer G, Hübel K, Greb A, Engert A, Bohlius J. Corticosteroids for preventing graft-versus-host disease after allogeneic myeloablative stem cell transplantation. Cochrane Database Syst Rev. 2008. doi:10.1002/14651858.CD004885.pub2

33. Walters JAE, Tan DJ, White CJ, Wood-Baker R. Different durations of corticosteroid therapy for exacerbations of chronic obstructive pulmonary disease. Cochrane Database Syst Rev. 2018. doi:10.10 02/14651858.CD006897.pub4

34. Stolz D, Christ-grain M, Bingisser R, et al. Antibiotic treatment of exacerbations of COPD: a randomized, controlled trial comparing procalcitonin-guidance with standard therapy. Chest. 2007;131: 9-19. doi:10.1378/chest.06-1500

35. Hwang J, Weiss RE. Steroid-induced diabetes: a clinical and molecular approach to understanding and treatment. Diabetes Metab Res Rev. 2014. doi:10.1002/dmrr

36. Vestergaard P, Rejnmark L, Mosekilde L. Fracture risk in patients with chronic lung diseases treated with bronchodilator drugs and inhaled and oral corticosteroids. Chest. 2007;132:1599-1607. doi:10. 1378/chest.07-1092

37. Henzen C, Suter A, Lerch E, Urbinelli R, Schorno XH, Briner VA. Suppression and recovery of adrenal response after short-term, high-dose glucocorticoid treatment. Lancet. 2000. doi:10.1016/ S0140-6736(99)06290-X

38. Gurwitz JH, Bohn RL, Glynn RJ, Monane M, Mogun H, Avorn J. Glucocorticoids and the risk for initiation of hypoglycemic therapy. Arch Intern Med. 1994;154:97. doi:10.1001/archinte.154.1.97

39. Plat L, Byrne MM, Sturis J, et al. Effects of morning cortisol elevation on insulin secretion and glucose regulation in humans. $A m$ J Physiol Metab. 2017. doi:10.1152/ajpendo.1996.270.1.e36

40. Wise JK, Hendler R, Felig P. Influence of glucocorticoids on glucagon secretion and plasma amino acid concentrations in man. $J$ Clin Invest. 1973;52:2774-2782. doi:10.1172/JCI107473

41. Van Raalte DH, Ouwens DM, Diamant M. Novel insights into glucocorticoid-mediated diabetogenic effects: towards expansion of therapeutic options? Eur J Clin Invest. 2009;39:81-93. doi:10.1111/ j.1365-2362.2008.02067.x
42. Cadoudal T, Leroyer S, Reis AF, et al. Proposed involvement of adipocyte glyceroneogenesis and phosphoenolpyruvate carboxykinase in the metabolic syndrome. Biochimie. 2005;87:27-32. doi:10. 1016/j.biochi.2004.12.005

43. Franckhauser-vogel S, Antras-ferry J, Robin D, Robin P, Forest C. Transcriptional and posttranscriptional mechanisms of glucocorticoid- mediated repression of phosphoenolpyruvate carboxykinase gene expression in adipocytes. $J$ Cell Biochem. 1997;66:386-393. doi:10.1002/(SICI)1097-4644(19970901)66:3<38 $6:: \mathrm{AID}-\mathrm{JCB} 10>3.0 . \mathrm{CO} ; 2-\mathrm{D}$

44. Van Raalte DH, Nofrate V, Bunck MC, et al. Acute and 2-week exposure to prednisolone impair different aspects of $\beta$-cell function in healthy men. Eur J Endocrinol. 2010;162:729-735. doi:10.1530/ EJE-09-1034

45. Van Raalte DH, Brands M, Van Der Zijl NJ, et al. Low-dose glucocorticoid treatment affects multiple aspects of intermediary metabolism in healthy humans: a randomised controlled trial. Diabetologia. 2011;54:2103-2112. doi:10.1007/s00125-011-2174-9

46. Çağdaş DN, Paç FA, Çakal E. Glucocorticoid-induced diabetic ketoacidosis in acute rheumatic fever. $J$ Cardiovasc Pharmacol Ther. 2008;13:298-300. doi:10.1177/1074248408326609

47. Hwang K, Smith JF, Coward RM, et al. Evaluation of the azoospermic male: a committee opinion. Fertil Steril. 2018;109(5):777-782. doi:10.1016/j.fertnstert.2018.01.043

48. Lin CS, Liu CC, Yeh CC, et al. Diabetes risks and outcomes in chronic obstructive pulmonary disease patients: two nationwide population-based retrospective cohort studies. PLoS One. 2017. doi:10.1371/journal.pone.0181815

49. Suissa S, Kezouh A, Ernst P. Inhaled corticosteroids and the risks of diabetes onset and progression. Am J Med. 2010;123:1001-1006. doi:10.1016/j.amjmed.2010.06.019

50. Price DB, Russell R, Mares R, et al. Metabolic effects associated with ICS in patients with COPD and comorbid type 2 diabetes: a historical matched cohort study. PLoS One. 2016;11:e162903. doi:10.1371/ journal.pone. 0162903

51. Niewoehner DE, Erbland ML, Deupree RH, et al. Effect of systemic glucocorticoids on exacerbations of chronic obstructive pulmonary disease. Department of Veterans Affairs Cooperative Study Group. N Engl J Med. 1999;340:1941-1947. doi:10.1056/NEJM199906243402502

52. Shah S, Sonawane P, Vaidya S, Salvi S, Nahar P. Pulmonary function tests in type 2 diabetes mellitus and their association with glycemic control and duration of the disease. Lung India. 2013;30:108. doi:10.4103/0970-2113.110417

53. Litonjua AA, Lazarus R, Sparrow D, DeMolles D, Weiss ST. Lung function in type 2 diabetes: the Normative Aging Study. Respir Med. 2005;99:1583-1590. doi:10.1016/j.rmed.2005.03.023

54. Aparna A. Pulmonary function tests in type 2 diabetics and non-diabetic people - A comparative study. J Clin Diagnostic Res. 2013. doi: $10.7860 / J C D R / 2013 / 6182.3237$

55. Lange P, Groth S, Mortensen J, et al. Diabetes mellitus and ventilatory capacity: a five year follow-up study. Eur Respir J. 1990;3 (3):288-292.

56. Lim SY, Rhee EJ, Sung KC. Metabolic syndrome, insulin resistance and systemic inflammation as risk factors for reduced lung function in korean nonsmoking males. J Korean Med Sci. 2010;25:1480. doi: $10.3346 / \mathrm{jkms} .2010 .25 .10 .1480$

57. Kinney GL, Black-shinn JL, Wan ES, et al. Pulmonary function reduction in diabetes with and without chronic obstructive pulmonary disease. Diabetes Care. 2014;37:389-395. doi:10.2337/dc13-1435

58. Miller J, Edwards LD, Agustí A, et al. Comorbidity, systemic inflammation and outcomes in the ECLIPSE cohort. Respir Med. 2013;107:1376-1384. doi:10.1016/j.rmed.2013.05.001

59. Geerlings SE, Hoepelman AIM. Immune dysfunction in patients with diabetes mellitus (DM). FEMS Immunol Med Microbiol. 1999; 26:259-265. doi:10.1016/S0928-8244(99)00142-X 
60. Alves C, Casqueiro J, Casqueiro J. Infections in patients with diabetes mellitus: a review of pathogenesis. Indian J Endocrinol Metab. 2012;16:27. doi:10.4103/2230-8210.94253

61. Gan YH. Host susceptibility factors to bacterial infections in type 2 diabetes. PLoS Pathog. 2013;9:e1003794. doi:10.1371/journal.ppat.10 03794

62. Yeh HC, Punjabi NM, Wang NY, et al. Cross-sectional and prospective study of lung function in adults with type 2 diabetes. Diabetes Care. 2008;31:741-746. doi:10.2337/dc07-1464

63. Junior LA, Kretzmann NA, Tieppo J, Picada JN, Dias AS, Marroni NA. Lung alterations in a rat model of diabetes mellitus: effects of antioxidant therapy. J Bras Pneumol. 2010. doi:10.1590/ S1806-37132010000500009[pii]

64. Gill SK, Hui K, Farne H, et al. Increased airway glucose increases airway bacterial load in hyperglycaemia. Sci Rep. 2016;6. doi:10.10 38/srep27636

65. Mallia P, Webber J, Gill SK, et al. Role of airway glucose in bacterial infections in patients with chronic obstructive pulmonary disease. J Allergy Clin Immunol. 2018;142:815-823.e6. doi:10.1016/j.jaci.20 17.10 .017

66. Moretti M, Cilione C, Marchioni A, Tampieri A, Fracchia C, Nava S. Incidence and causes of non-invasive mechanical ventilation failure after initial success. Thorax. 2000;55:819-825. doi:10.1136/thorax.55.10.819

67. Loukides S, Polyzogopoulos D. The effect of diabetes mellitus on the outcome of patients with chronic obstructive pulmonary disease exacerbated due to respiratory infections. Respiration. 1996;63: 170-173. doi:10.1159/000196539

68. Walters JAE, Tan DJ, White CJ, Gibson PG, Wood-Baker R, Walters EH. Systemic corticosteroids for acute exacerbations of chronic obstructive pulmonary disease. Cochrane Database Syst Rev. 2014;9:CD001288. doi:10.1002/14651858.CD001288.pub4

69. Davies L, Angus RM, Calverley PMA. Oral corticosteroids in patients admitted to hospital with exacerbations of chronic obstructive pulmonary disease: a prospective randomised controlled trial. Lancet. 1999;354:456-460. doi:10.1016/S0140-6736 (98)11326-0

70. Walters JA, Wang W, Morley C, Soltani A, Wood-Baker R. Different durations of corticosteroid therapy for exacerbations of chronic obstructive pulmonary disease. Cochrane Database of Syst Rev. 2011. doi:10.1002/14651858.cd006897.pub2

71. Wouters EF. Management of severe COPD. Lancet. 2004;36 4:883-895. doi:10.1016/S0140-6736(04)16984-5

72. Leuppi JD, Schuetz P, Bingisser R, et al. Short-term vs conventional glucocorticoid therapy in acute exacerbations of chronic obstructive pulmonary disease: the REDUCE randomized clinical trial. $J \mathrm{Am}$ Med Assoc. 2013;309:2223. doi:10.1001/jama.2013.5023

73. Walters JAE, Walters EH, Wood-baker R. Oral corticosteroids for stable chronic obstructive pulmonary disease [Systematic Review]. Cochrane Database Syst Rev. 2005. doi:10.1002/14651858.CD005374
74. Decramer M, De Bock V, Dom R. Functional and histologic picture of steroid-induced myopathy in chronic obstructive pulmonary disease. Am J Respir Crit Care Med. 1996;153:1958-1964. doi:10.1164/ajrccm.153.6.8665061

75. McEvoy CE, Ensrud KE, Bender E, et al. Association between corticosteroid use and vertebral fractures in older men with chronic obstructive pulmonary disease. Am J Respir Crit Care Med. 1998;157:704-709. doi:10.1164/ajrccm.157.3.9703080

76. Horita N, Miyazawa N, Morita S, et al. Evidence suggesting that oral corticosteroids increase mortality in stable chronic obstructive pulmonary disease. Respir Res. 2014;15:37. doi:10.1186/1465-9921-15-37

77. Singh D, Agusti A, Anzueto A, et al. Global strategy for the diagnosis, management, and prevention of chronic obstructive lung disease: the GOLD science committee report 2019. Eur Respir J. 2019;53(5):1900164. doi:10.1183/13993003.00164-2019

78. Calverley PMA, Anderson JA, Celli B, et al. Salmeterol and fluticasone propionate and survival in chronic obstructive pulmonary disease. $N$ Engl J Med. 2007;356:775-789. doi:10.1056/NEJMoa063070

79. Wedzicha JA, Miravitlles M, Hurst JR, et al. Management of COPD exacerbations: a European Respiratory Society/American Thoracic Society guideline. Eur Respir J. 2017. doi:10.1183/13993003.00791-2016

80. Global Initiative for Chronic Obstructive Lung Disease. Chronic Obstructive Pulmonary Disease Updated 2010 Global Initiative for Chronic Obstructive Lung Disease; 2016. doi:10.1097/00008483200207000-00004

81. National Institute for Health and Care Excellence. Chronic obstructive pulmonary disease in over 16s: diagnosis and management; 2019. Available from: https://www.nice.org.uk/guidance/NG115. Accessed March 3, 2020.

82. Laue J, Reierth E, Melbye H. When should acute exacerbations of COPD be treated with systemic corticosteroids and antibiotics in primary care: a systematic review of current COPD guidelines. $N p j$ Prim Care Respir Med. 2015. doi:10.1038/npjpcrm.2015.2

83. Ceviker Y, Sayiner A. Comparison of two systemic steroid regimens for the treatment of COPD exacerbations. Pulm Pharmacol Ther. 2014;27:179-183. doi:10.1016/j.pupt.2013.03.004

84. Aaron SD, Vandemheen KL, Hebert P, et al. Outpatient oral prednisone after emergency treatment of chronic obstructive pulmonary disease. N Engl J Med. 2003;348:2618-2625. doi:10.1056/nejmoa023161

85. Alía I, De La Cal MA, Esteban A, et al. Efficacy of corticosteroid therapy in patients with an acute exacerbation of chronic obstructive pulmonary disease receiving ventilatory support. Arch Intern Med. 2011;171:1939. doi:10.1001/archinternmed.2011.530

86. Bafadhel M, McKenna S, Terry S, et al. Blood eosinophils to direct corticosteroid treatment of exacerbations of chronic obstructive pulmonary disease: a randomized placebo-controlled trial. Am J Respir Crit Care Med. 2012;186:48-55. doi:10.1164/rccm.201108-1553OC

87. Bafadhel M, Pavord ID, Russell REK. Eosinophils in COPD: just another biomarker? Lancet Respir Med. 2017;5:747-759. doi:10.1016/S2213-2600(17)30217-5

\section{Publish your work in this journal}

The International Journal of COPD is an international, peer-reviewed journal of therapeutics and pharmacology focusing on concise rapid reporting of clinical studies and reviews in COPD. Special focus is given to the pathophysiological processes underlying the disease, intervention programs, patient focused education, and self management protocols. This journal is indexed on PubMed Central, MedLine and CAS. The manuscript management system is completely online and includes a very quick and fair peer-review system, which is all easy to use. Visit http://www.dovepress.com/testimonials.php to read real quotes from published authors. 